\title{
Selection of tachymetry spacing in the process of monitoring of construction projects
}

\author{
Oleg Rubtsov*, Ramidin Alisultanov and Nina Rogova \\ Moscow State University of Civil Engineering, Yaroslavskoe shosse, 26, Moscow, 129337, Russia
}

\begin{abstract}
The urbanization of territories and the increase in density of urban development cause the necessity of introduction of improved structural solutions into the construction practice. This is also connected with both the erection of higher buildings with longer span structures and the use of non-standard methods for the analysis of structures. The introduction of modern structural patterns lessens considerably the weight of structures, reduces the consumption of materials and cuts the construction production costs. At the same time, the responsibility for the construction projects enhances. A systematic control over the state of structures including a quasi-continuous one, allows us to reveal the very beginning of destructive processes and to take measures for their liquidation. One of monitoring methods is the tachymetry survey of positions of a number of adjusting marks fixed at the structural elements. The non-reflection mode of operation of tachymetry survey allows lifting the restrictions for the number of points under observations. The combination of the afore-said factors determines the urgency of the use of the tachymetry as a tool for monitoring the state of the construction project.
\end{abstract}

The subject of the study: the subject of the present research work is the methodology of selection of tachymetry spacing during the deformation monitoring of a construction project. The tachymetry can be carried out both in the mode of focusing on pre-established marks, and in the non-reflection mode through the points on the structure. The disadvantage of the first method is the need of installation of lightreflecting marks, which is not always possible due to some technical and/or aesthetic reasons and may lead to a significant increase in the cost of monitoring. The disadvantage of the second method is a reduced accuracy of the measurements. A wide incremental step may lead to the failure of detection of deformation processes, a narrow step means a considerable increase in the monitoring time and an unjustified rise in the cost of monitoring.

Objectives: the purpose of this research work is the optimization of tachymetry spacing, which will reveal all deviations of structural elements from their permanent positions by a value exceeding the accuracy of measurements.

Materials and methods: the initial material for the study included the results of geodetic observations carried out at various construction projects, in particular, the tachymetry results. The method of study includes the

\footnotetext{
* Corresponding author: AlisultanovRS@mgsu.ru
} 
comparing of the limiting admissible curvature value to the minimum deformation value measured with the tachymeter accuracy.

Results: a methodology is suggested for the selection of the tachymetry survey step. On its basis, a formula for the determination of a step value is offered that takes into account the geometry of the structure, the strain capacity of the material and the accuracy of the survey.

Conclusions: the obtained results allow us to optimize the number of the observation points during the tachymetry survey and to ensure the detection of all destructive effects associated with structural geometry changes at the construction project. The descriptions of the methodology are recommended for their application in the development of geodetic monitoring programmes.

\section{Introduction}

During the maintenance process of construction projects, their structural elements are subject to various effects causing the changes in their forms. These changes are directly connected with the geometry of structural elements (their thickness values), the elasticity modulus of the material and the mechanical stress values in the elements. The monitoring of the state of a construction project as a system of observations over the parameters of its constituents carried out with a given periodicity allows us to reveal timely the destructive processes and to take measures for their liquidation. Thus, the safety of the further maintenance of the construction project may be provided for.

\section{Methods}

The geodetic monitoring is one of the most effective methods of monitoring of structural elements and structures. As a rule, the observations concern the relative displacements of measuring marks fixed at the structures under observation. The disadvantages of these observations are a limited number of measuring marks and the impossibility of determination of structure deformations before the start of the observation.

The use of a greater number of measuring marks is not always possible because of aesthetic or technical considerations. The 3-coordinates tachymetry survey (carried out in a non-reflection operation mode) does not require the installation of stationary measuring marks. The evaluation of deformations before the observation period may be performed through the mathematical processing of data with the consideration of the hypothesis concerning the initial form of the surface under study. This work includes the consideration of quantitative and qualitative characteristics of initial data for such a processing.

Any structure is subject to some deformations under the influence of design or nondesign loads. Through the deformation values, the applied loads may be evaluated, and the possible further use of the structure may be assessed. The problem is to choose the optimum number of measuring marks for the survey allowing the determination of all possible structure deformations.

In 1933, V.A. Kotel'nikov formulated the theorem: if an analog signal does not contain any frequencies higher than $f_{\max }$ in its spectrum, then it is possible to restore ideally exact this signal through the discrete readings taken with a frequency higher than $2 f_{\max }$. If we determine the highest possible static structure deformations, we determine the survey frequency as well. In the Kotel'nikov's theorem, the frequency is determined through the signal amplitude as a function of time. In our case, the frequency is a function of the deformation values depending on the length or the surface of the structural element under 
observation. The problem is to determine the minimum extent of the deformed area which we are able to register.

\section{Results}

For the solution of the afore-stated problem, we introduced the assumption that the deformation of a structural element in its cross-section normal to its initial surface may be described by an arc of the circle with the radius $R$. Denote $A$ the minimum deformation value which we are able to determine using some geodetic measurements. It is seen from Fig.1 (assuming $A<<R$ ) that

$$
L=\sqrt{2 R A}
$$

The value of $A$ is determined by the accuracy of measurements, while the value of $R$ is characterized by the physical properties of the structural element. Assuming, as the first approximation, the isotropy and the uniformity of the element under study, we can use the well-known formula for the calculation of the curvature radius [38]:

$$
1 / R=M / E J
$$

where $M$ - bending moment, $E$ - elasticity modulus of the material, $J$-moment of inertia of the cross-section.

The bending moment may be expressed through the mechanical stresses $\sigma$, arising in the structure and the section modulus $W: M=\sigma W$ in its turn, $W=2 \mathrm{~J} / t$, where $t-$ thickness of the element under study. Also, $\sigma=E \varepsilon$, where $\varepsilon$ - relative deformation.

Substituting the expressions for $M, W$ and $\varepsilon$ into (2), we obtain:

$$
R=t / 2 \varepsilon
$$

Thus, a possible curvature radius value is calculated. Substituting this value into (1), we obtain:

$$
L=\sqrt{t A / \varepsilon}
$$

Thus, we have an expression for the determination of the maximum incremental step of tachymetry survey, which allows us to reveal the bending value $A$ of the structural element.

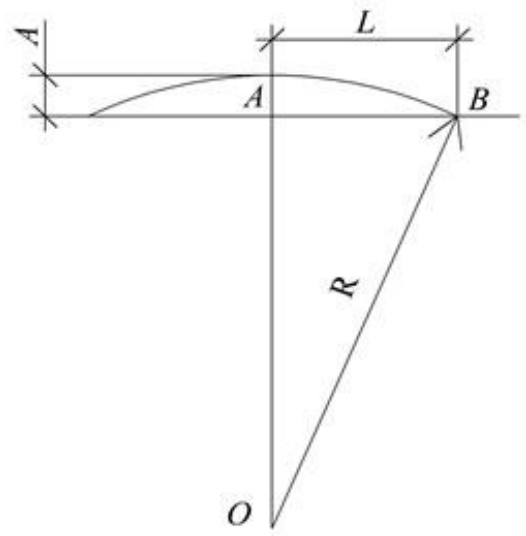

Fig. 1. Determination of the extent of a deformed area in a structural element. 
As the first approximation, we can consider the limiting relative deformation value for construction materials to be equal to $1 \cdot 10^{-3}$. The value of $A$ cannot be less than the accuracy of measurement taken equal to $2 \mathrm{~mm}$, i.e. $A=2 \mathrm{~mm}$. The thickness of the wall from prefabricated reinforced concrete is usually equal to $250 \mathrm{~mm}$. Substituting these approximate values into (4), we obtain the measurement step value of $700 \mathrm{~mm}$.

Here the value of $R$ (calculated from (1)) will be approximately equal to $120 \mathrm{~mm}$. Considering the limiting tensile relative deformation to be equal to $1,5 \cdot 10^{-4}$ and the building wall thickness to be not less than $750 \mathrm{~mm}$, we obtain the measurement step value of $3000 \mathrm{~mm}$ and the curvature radius value of more than $2 \mathrm{~km}$.

The method has been applied in the process of inspection of a building with a variable number of storeys. Fig. 2 presents the isometric lines drawn with the step value of $10 \mathrm{~mm}$ according to the initial survey points which are presented as well.

Using the afore-said formulas, we can determine the measurement step for a 3 coordinates tachymetry survey allowing us to reveal the areas, which are potentially dangerous for the structure under observation.

If the number of measurement points is sufficient for the determination of the functional dependence of the deflection $y$ on the $x$-coordinate, the curvature radius $R$ may be obtained through the formula

$$
R=\frac{\left(1+\left(y^{\prime}\right)^{2}\right)^{3 / 2}}{\left|y^{\prime \prime}\right|}
$$

Considering the location of isometric lines in the area with the maximum deformation gradient (central area in Fig.2), we can approximately calculate the surface curvature radius value of about $35 \mathrm{~m}$.

Comparing the calculated values to the afore-said curvature radii, we note that the wall curvature is inadmissible.

This fact may be connected with both the loading conditions and the initial surface curvature at the moment of the building erection. Comparing the obtained curvature values to the standard tolerance values for the moment of the building erection, we can come to a conclusion concerning the present state of the building.

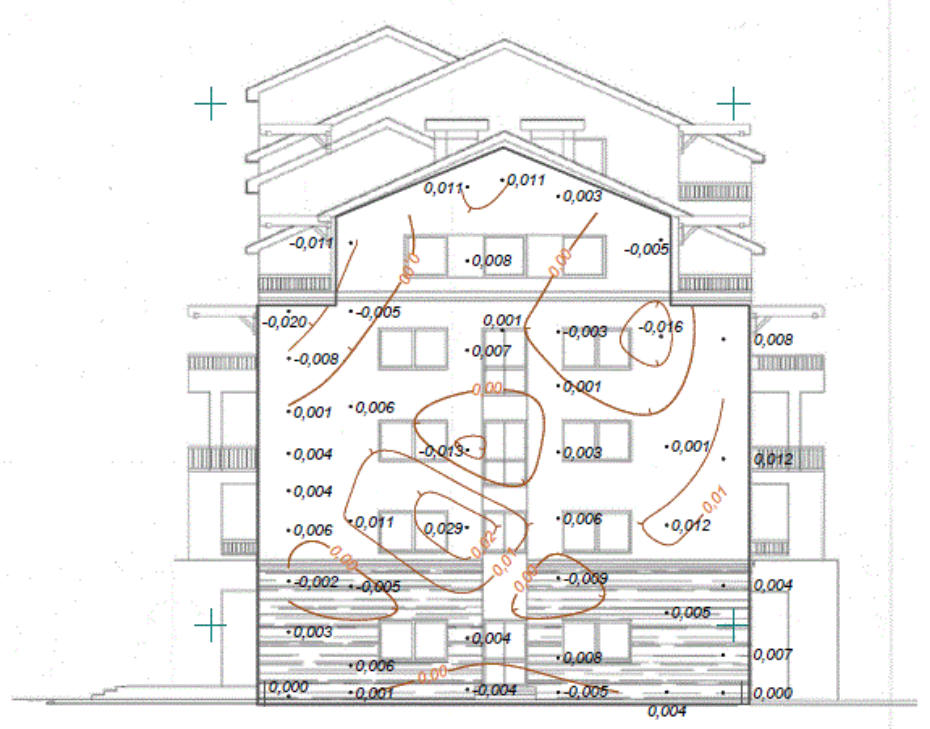

Fig. 2. Isometric lines for the end-face wall of a four-storey building with a superstructure. 


\section{Discussion}

The necessity of monitoring is noted in many published works, in particular, in [1-9]. The monitoring systems for historic buildings are of particular importance [10]. There are different methods and means of monitoring, e.g. the work [11] considers the monitoring of engineering state of structural elements and notes the importance of measurement of forms of natural oscillations for these elements. The systems of control over the engineering state of structures are being developed on the basis of the monitoring systems [12] as well as of the simulation of deformation processes [13].

Among different monitoring systems, we should note the geodetic monitoring, i.e. the system observations over the structure deformations. The necessity and the prospects of geodetic monitoring are mentioned in [14-16]. The factual disposition of structural elements considerably influences their strength and stability [17]. A thorough review of apparatus and methods of observations over the strains in structures is given in [18]. The experimental studies of the methods of determination of control positions are described in [19]. A space model of a structure considers the data obtained from the deformation monitoring allowing the determination of the most vulnerable places [20-22]. We should differentiate once-only, periodic and continuous observations over the deformations [23]. The experience of the use of automated deformation monitoring systems at the Olympic structures has been presented in [24], that in a dense city development - in [25], that for hydro-engineering structures - in [26] and that for historic buildings - in [27]. The monitoring of linear strains is described in [28] and that of non-linear surfaces is stated in [29]. The control over the strains may be carried out by different ways: laser scanning [3032] (which allows the determination of seismic loadings, according to [33]); photogrammetry [34]; determination of drill-hole inclination and direction [35] and tachymetry survey [36].

The systems of monitoring of engineering state (in accordance with [37]) are installed at potentially dangerous, hazardous, complex and unique structures. In accordance with [38], in case of a limited serviceability of buildings or structures, their further use is possible with the monitoring of their engineering state.

\section{Conclusions}

The use of the afore-mentioned methodology provides for the achievement of the purpose of the study: the optimization of the tachymetry survey step. Placing the geodetic marks (in case of geodetic survey with measuring marks) or focusing the tachymeter axis of sight on given points (in case of non-reflection operation mode), we will be able to determine all possible deformations of the structures which do not cause their destruction. Thus, from one hand, the cost of production of works decreases, and, from the other hand, the quality of the works improves due to the exposure of all possible deformations of the structures. Comparing the factual geometry of the structure to its design disposition, we are able to draw a conclusion about the degree of external effects as well as about the state of the structure at the moment of registration of measurements. A periodic tachymetry survey allows us to reveal the dynamics of destructive processes and to take timely measures for the prevention of development of hazardous situations.

To settle the question of the survey step once and for all, it is necessary to study the accuracy of focusing the tachymeter for different operation modes including ones with consideration of the quality of the surface under supervision, which may serve as a subjectmatter for further studies in the field. 


\section{References}

1. Kustikova Yu. O., Podgornykh S.E. Monitoring of technical condition of buildings and structures as an integral part of an integrated approach for timely control of urban environment objects, 11, 107-11 (2016)

2. Ginzburg A., Kachanov S. Methodology for building automated systems for monitoring engineering (load-bearing) structures, and natural hazards to ensure comprehensive safety of buildings and structures (Int. J. of Appl. Eng. Res., 11, 1660-1665, 2016)

3. Svalova V. Landslides modeling, monitoring, risk management and risk reduction, 11, 43-52 (2016)

4. Demenev A.V. Information modeling of operation of buildings and structures. Advanced research in science: theory and practice (The Coll. of Sch. Pap.,195-199, 2016)

5. Ruvinskaya V.M., Troynina A.S., Berkovich E.L., Bilovzorov O.O. Rules of expert system for safety monitoring: checking on completeness and consistency (Proc. of Odessa Polyt. Un., 2, 103-110, 2015)

6. Zavalishin S.I., Khlystunov M.S., Mogilyuk J.G. Problems of reliability of design modeling and monitoring of the technical condition of buildings and structures, 4, 3541 (2015)

7. Simonyan V.V., Shmelev N.A. Zaitsev A.K. Geodetic monitoring of buildings and structures as a basis for safety control during construction and operation of engineering structures Moscow, 2 (2016)

8. Simonjan V.V., Shmelin N.A., Zaitsev A.K. Geodetic monitoring of buildings and structures (MSUoCE Library, 2015)

9. Platonov V., Shaposhnikov V., Aleksandrov A., Gaina A. Development and application of monitoring systems for increasing reliability and safety of vessels and offshore structures (ISOPE, 646-650, 2016)

10. Shesterov E.A., Panin A.N. Special aspects of surveying structures of historic buildings in St.-Petersburg (Integr, partn. and innov. in build. sc. and educ., MSUoCE, 298-302, 2017)

11. Gaidaichuk V.V., Kotenko K.E., Tkachenko I.A. Mathematical method of diagnostic technical condition of the large-scale building structure (Wschodnioeuropejskie Czasopismo Naukowe, 17, 105-114, 2017)

12. Zapashtshikova N.P. Technique of management of technical condition and estimation of durability of hinged ventilated facades (Integr, partn. and innov. in build. sc. and educ., MSUoCE, 821-825, 2017)

13. Sokolov M.V., Prostov S.M. Modeling of geo-mechanical processes in case of uneven settling of foundation structures (Coal in the 21st Century: Mining, Proc. and Saf., 206-212, 2016)

14. Mel'kumov V.N., Tkachenko A.N., Kazakov D.A., Khakhulina N.B. Prospects for applying geodetic methods for monitoring deformations of pneumatic formwork (Sc. Journ. of Constr. and Arch., 37, 51-58, 2015)

15. Simonyan V.V., Shmelin N.A. The need for geodetic control for monitoring the displacement of buildings and structures, 4, 60-64 (2015)

16. Shevchenko A.A., Burtasova A.E., Glazkov R.E. The need to perform permanent geodetic deformation monitoring (KSTU, 10, 39-48, 2016) 
17. Belostotsky A.M., Akimov P.A., Kaytukov T.B., Petryashev N.O., Petryashev S.O., Negrozov O.A. Strength and stability analysis of load-bearing structures of evolution tower with allowance for actual positions of reinforced concrete structural members, 53, 95-102, (2016)

18. Morozov A.A., Gribkova L.A., Shapovalov V.L. Overview of techniques for monitoring deformations in instrumental survey of buildings and structures (KSTU, 8, 64-74, 2016)

19.Shekhovtsov G.A., Shekhovtsova R.P., Ivenin D.P., Raskatkina O.V. Experimental studies of ways to control the spatial situation of building structures (Geod. and cartogr., 4, 7-12, 2017)

20. Seredovich V.A., Avrunev E.I., Plyusnina E.S. Construction of a spatial model of an engineering structure in the implementation of deformation monitoring (Interexpo Geo-Siberia, 2, 89-97, 2016)

21. Barinova T.A., Katrich A.E. Deformation monitoring of buildings and structures (Sc. ach. and disc. of modern youth, 1575-1576, 2017)

22. Parkhomenko N.A., Sabirov R.R. Creation of a spatial model of the deformation process based on the results of geodetic monitoring of the building sludge (Act. probl. and persp. of develop. of geodesy, land manag. and Cadastr. Regi. in a market ec., 155-159, 2017)

23. Bandurov V.I., Gura D.A., Tereshtshenko S.V., Suslov D.S., Tulyaev I.A., Ignat'ev V.S. The difference between constant and periodic monitoring of deformations. Prospects for implementation in production (Nauka. Tehnika. Tehnologii, 2, 80$85,2016)$

24. Shakhraman'yan A.M., Kolotovichev Yu.A. Experience in the use of automated systems for monitoring the deformation state of load-bearing structures at Olympic facilities Sochi-2014 (Vestnik MGSU, 12, 92-105, 2015)

25. Kazantsev A.I. Geodetic monitoring of deformations of buildings and structures in conditions of compacted urban development (Fund. and appl. res. in the mod. world, 12, 127-129, 2015)

26. Oleinik A.Yu., Makshanov A.V., Marley V.E. Development of a monitoring system for deformations of hydraulic structures based on Internet technologies and microcontrollers (Vestnik GUMIR, 29, 215-222, 2015)

27. Zenoni A. Historical building stability monitoring by means of a cosmic ray tracking system (ANIMMA, 7465542, 2015)

28. Usanov S.V., Ruchkin V.I., Zheltysheva O.D. Monitoring linear deformation of buildings and structures (Journ. of Mining Sc., 4, 724-729, 2015)

29. Petrochenko A.V., Konyakhin I.A. Remote optoelectronic sensors for monitoring of nonlinear surfaces (SPIE, 950626, 2015)

30. Kuznetsova I., Kuznetsova D., Rakova X. The use of surface laser scanning for creation of a three-dimensional digital model of monument, 100, 1625-1633, (2015)

31. Takhirov S., Mosalam K.M., Moustafa M.A., Myagkova L., Quigley B. Laser scanning, modeling, and analysis for damage assessment and restoration of historical structures (COMPDYN, 2375-2395, 2015)

32. Gura T.A., Gribova E.A. Prospects for the introduction of ground-based laser scanning in the monitoring of buildings and structures (Professional goda, 123-128, 2017) 
33. Rovithis E., Makra K., Savvaidis A., Kirtas E., Marini E., Bliziotis D., Maltezos E., Pitilakis D. Assessment of seismic loading on structures based on airborne lidar data from the kalochori urban area (n. Greece) [SPIE, RSCy, 96880, 2016)

34. Golovina S., Kanyukova S. Photogrammetry and laser scanning for reconstruction and restoration of historical buildings (MATEC Web of Conf., 73, 1008, 2016)

35. Hiller B. Digital inclinometers in automated geodetic monitoring of deformations (Geodesy and aerial photography, 6, 23-30, 2015)

36. Shevchenko G.G., Gura D.A., Zheltko Ch.N. Determination of the coordinates of points by an electronic tachymeter for monitoring the structure (Vestnik KRSU, 1, 174-176, 2017)

37. Kotel'nikov V.A. The capacity of the "ether" and wire in telecommunications (UFN, 176 762-770, 2006)

38. Vardanyan G.S. Resistance of materials with the fundamentals of the theory of elasticity and plasticity (M. ASV, 1995) 